\title{
Review
}

\section{Learning science in informal environments: people, places and pursuits. A review by the US National Science Council}

\author{
Paola Rodari
}

\author{
P. Bell, B. Lewenstein, A.W. Shouse and M.A. Feder (eds.), Learning Science in Informal \\ Environments: People, Places, and Pursuits, The National Academy Press (2009)
}

\begin{abstract}
In January this year, the US saw the publication of the preview of an impressive review work on the practices and the studies concerning learning science outside schools and universities, i.e. what is referred to as informal education.

The document, promoted by the National Science Council of scientific academies (National Academy of Science, National Academy of Engineering and Institute of Medicine), is the result of the work by a committee comprising 14 specialists who collected, discussed and then organized hundreds of documents on pedagogical premises, places, practices and pursuits concerning scientific informal education.

Nobody doubts that museums, magazines, after-school activities, science festivals and any other science communication offers have a positive impact on the people's knowledge, attitudes and behaviours. But what do we really know about what actually happens in these experiences? What sense should be given to the word "learning" in these cases? Do the different communication tools or environments have also a different impact? What factors make them more or less effective? These are the main questions the document wants to answer, carefully evaluating the present state of the art.
\end{abstract}

In January this year, the US saw the publication of the preview of an impressive review work on the practices and the studies concerning learning science outside schools and universities, i.e. what is referred to as informal education.

The document, ${ }^{1}$ promoted by the National Science Council of scientific academies (National Academy of Science, National Academy of Engineering and Institute of Medicine), is the result of the work by a committee comprising 14 specialists who collected, discussed and then organized hundreds of documents on pedagogical premises, places, practices and pursuits concerning scientific informal education.

The premise of the work is this: every year, millions of American citizens of any age live experiences which concern science and technology and are not included in the traditional educational paths. They visit a science museum, they attend a lecture or a science show, they participate in an after-school activity or a workshop, they read a book or a magazine of science popularization, they participate in the activities of an environmental association or of a scuba-diving club, or they simply talk about science as they have some health issues.

Nobody doubts these are all experiences with a positive impact on people's knowledge, attitudes, behaviours.

But what do we really know - through observation and measurement - about what actually happens in these experiences? What sense should be given to the word "learning", in these cases? Do the different communication tools or environments have also a different impact? What factors make them more or less effective? These are the main questions the document wants to answer, carefully evaluating the present state of the art. This work has the great quality of patiently analyzing hundreds of documents and 
publications, and the great limitation of exclusively focussing on what happens in the United States, with some minimal (yet insufficient) references to what people think and write in the UK.

The experts' work followed these steps:

1. they explored the theoretical foundations of informal education;

2. they identified and defined the strands of learning in informal environments;

3. they reviewed the places where people of any age have learning experiences: real places (for example museums) or virtual (TV, magazines...), designed especially to communicate science or established for other purposes, but where science and technology have a significant presence in any case;

4. they reviewed the studies aimed at identifying the significant variables of this type of learning and therefore to measure them;

5. finally, they produced some recommendations on the work still to be done to enhance these environments, as well as to measure their impact.

As the document contents cannot be thoroughly discussed here, only the most interesting parts will be highlighted.

\section{The different sides of learning science}

While there is no doubt that informal education experiences can really promote some learning, the crucial issue, which certainly is neither new nor scarcely explored, but is still pending, is to define what this type of learning actually is. Conceiving it (and consequently measuring it) only in terms of acquisition of information and notions (as normally happens in the evaluation of educational paths) is evidently reductive. It is plain to everyone that informal education experiences have strong nonconceptual and non-verbal components, and quite emotional, aesthetical, motivational and social ones.

The review of the most popular (in the US) theories on informal learning does not offer - for those who are familiar with the field - any special novelty. Bitgood, Dierking, Falk, Hein are the mandatory references and in fact they are largely quoted. More original is the authors' attempt to provide a new conceptual framework in which to comprehend all the different aspects of informal learning, to subsequently use it as a framework through which you can reorganize the range of the offers (of places, products, experiences) and most of all of the research projects concerning informal contexts. The authors then identify six learning strands, which are frequently intertwined in the real world, but which need to be distinguished precisely to promote a convergence programme, both for operators practitioners and for researchers, towards a shared theoretical framework.

According to the authors, in any informal contexts, people:

Strand 1. Live interesting, involving and stimulating experiences, and are motivated to acquire new knowledge on the phenomena of the physical and natural world;

Strand 2. Are able to produce, understand, recall and use notions, explanations, arguments, models and facts related to science;

Strand 3. Manipulate, test, explore, predict, observe and give sense to the physical and natural world;

Strand 4. Reflect on science as a way to learn; on its processes, concepts and institutions; they reflect on their own learning process;

Strand 5. Participate in scientific and practical learning activities along with other people, using scientific terminology and specific instruments;

Strand 6. Think of themselves as people learning science and thus build an identity as persons who know, use and sometimes contribute to the production of scientific knowledge.

Some of those strands are also shared by school learning and formal learning in general, whereas, according to the authors, others are more specific to informal education environments. Specifically, they are strands 1 and 6, which focus on the strongly personal components of the learning experience: on the one hand experiences and emotions created through meeting science in informal education environments, and on the other hand the building process, also through these experiences, of a way to see yourself as a subject of experience and learning.

The attention paid to building a self-image as "science learner" or "being able to make/making science" is certainly one of the most interesting points of the review. The spreading and the deepening of the studies on gender, social and disadvantaged community diversity are increasingly highlighting that selfperception is a crucial factor in learning. The results of learning do not depend only on being more or 
less talented and/or on having more or less instruments available, but depend also on being considered and considering yourself able to learn. Those who think they are not able to learn (like those who affirm a priori that "science is not my thing") neither take the risk nor commit themselves to something, they do not have the courage either to follow their reasoning or to express it, and therefore put themselves in the condition of not learning, as if it were a prophecy coming true by itself. Therefore, building an identity as "somebody learning science" and as a "potential scientist" is probably a fundamental ingredient, almost a prerequisite, for a satisfactory experience also in informal education. ${ }^{2}$ Considering the importance the document places on the personal aspects of learning (also in the final recommendations, as mentioned later in this review), quite regrettably the authors did not mention many excellent European studies concerning precisely the links between self-image, image of scientists, motivation and interest; with a special focus on gender issues. Among them, it is worthwhile to mention the studies by the group of researchers working in the framework of the project Rose, the Relevance of Science Education (http://www.ils.uio.no/english/rose/). Although it is a project addressing innovation in formal education, the research projects which underpins it are very interesting also for those dealing with informal education. ${ }^{3}$

\section{People, communities and citizens}

In fact, the document contains many references to different identities (gender, communities, religion, access to knowledge), and to how they give rise to differences also in learning, and especially to how they should be integrated in a cultural offer paying attention to respecting diversity and inclusion.

As much as an individual's way of existing and perceiving is a fundamental variable in learning processes, a group and a community are places in which the knowledge is created, and they cannot be ignored. United States, the melting-pot country, has always been at the forefront in acknowledging and respecting the different groups living in the same territory.

However, the document completely overlooks another important aspect in the relation between science, technology and society, i.e. the knowledge linked to scientific citizenship. In Europe, this is the subject not only of the talk of researchers in social sciences, education and science communication, but also of many official and programmatic documents of national and community bodies and authorities; it is even the goal of many projects and actions promoted at different geographical levels. This concept may be put in simple terms, but when it becomes a programme, it may have deep consequences on a country's democratic set-up: in a knowledge-based society, to be a fully-accomplished citizen, you need to be able to take part in the debate on the directions that scientific and technologic research is to take, i.e. you need to be able to participate in their governance. Genetically modified organisms, in-vitro fertilization, energy sources... these are issues (among many others) in which citizens are required to express themselves at national or supranational international level. Those decisions are also necessary at local level, when it comes to waste disposal, public transports, energy production and consumption. They are issues dealt with by a democratic society by requesting the participation of experts, policy-makers, scientists, stakeholders, but also all the citizens. However, in order to participate, a citizen should possess a special set of abilities and knowledge which have to do with science, but that cannot be reduced to traditional and disciplinary scientific knowledge. Indeed, it is not about knowing specific facts or words (even though sometimes it is certainly indispensable), but it is also about knowing how to consider, evaluate and discuss ethical, social and economic aspects of scientific and technologic knowledge; it is about knowing and handling (though not in an expert-like way) specific instruments of reasoning, such as the calculation of the cost/benefit ratio of an action or some risk assessment. In some cases (consider patients' organizations), it means being involved in the framework of a democratic discussion which can even precede the production of applications, programmes or policies, in the co-production of scientific and technological knowledge. ${ }^{4}$

An increasingly higher number of informal education initiatives have the explicit purpose of promoting the establishment of this knowledge and the related practices. Consider science cafés, discussion games, participatory procedures such as citizens' juries or consensus conferences, but also the new genre of interactive exhibitions in which interaction also includes the chance for visitors to express their opinions and to compare them with one another.

Though it is extremely detailed in other aspects, quite sadly the document fails to consider this very aspect; maybe a seventh strand was needed in the classification outlined, or maybe scientific citizenship 
should have been at least highlighted mentioning the related specific awareness, knowledge and abilities, including them in the other six strands.

\section{Measuring learning}

A large part of the document is devoted to a review of the different methods used to define and to measure informal learning, and to a report of research results, ordering the information according to the above-mentioned six strands. Using these six aspects of learning as a leading thread certainly is a useful strategy to guide the reader through a bunch of studies which is now huge and uneven.

The document considers a significant number of (US) studies, and its main quality is precisely to provide the reader with a sort of annotated bibliography of what is known and thought about informal education.

In all the studies considered - the authors say - there is important evidence of the educational value of any informal education experience. Once again, the issue is to put some order in the jungle of theoretical premises, evaluation methods, and conclusions.

From facial expression observation to in-depth interviews, from measuring the use of online resources to tracking visitors' movements within an exhibition, the variety of research methods is huge, as much as the variety of places and activities that fall within the field of informal education; as much as the variety of the phenomena you may want to observe.

Looking beyond this large array of methods and results for a common ground, the authors identified some convergence points in research, which at the same time suggest the paths to be followed in the future work. The following are the most important theoretical problems which the authors suggest to consider in any future work, be it general research or the evaluation of the effectiveness of specific experiences or programmes:

- the outcomes of informal education experiences show up in very individual ways, which should be described also in a holistic manner: as individual learning paths are very personal and complex, therefore it is not possible to measure the outcomes of informal education by using only specific and spot indicators assumed to be able to describe any experience;

- $\quad$ these outcomes can even be unexpected, i.e. you may trace outcomes deriving from how a certain programme/event/context is structured (and therefore planned by those who designed it), but you may find also outcomes which were even totally unexpected;

- the outcomes may show up at different times. There are short-term outcomes, which are those mostly reported also because it is obviously much easier to do so, but there are also impacts which appear much later and can be extremely long-lasting, and maybe they are the most important ones, although the most difficult to record.

- informal learning has effects on individuals; on the other hand, it is also interesting to wonder what the impacts on entire communities are, both exploring the functioning of the group as a learning group, and trying to understand how a specific programme influences an entire community.

As the main player in informal learning is the one who learns, the future attempts in research (but also of those planning activities and products) cannot but follow the path of a deeper analysis of anything which is linked to an individual and to a groups of individuals. Obviously without leaving aside science with its nature and its realizations, the informal education field is becoming gradually less a place for transfer of notions, and gradually more a place for meeting and socializing.

\section{The tasks ahead of us}

The document ends by summarizing the conclusions of the various chapters and addressing some recommendations to the different players of informal education: educators, exhibition and programme designers, science communicators, researchers.

As to the professionals working in this field (educators, science communicators, but also researchers committed to outreaching), the authors recommend a better attention to producing projects with clear objectives and methods. Only specific and detailed planning will allow for a good work of evaluation but also of comparison with other experiences and environments. However, at the same time they ask experts 
not to look exclusively at their own specialized community, but on the contrary to also make the planning process a participatory one, including since the outset the educators in the communities addressed, as well as other experts or stakeholders, and most of all also the subjects the action is addressed to.

The educators in direct contact with the public should continue this inclusion process, integrating in their speech "questions, everyday language, concerns, world views, and histories, both their own and those of diverse learners. To do so they will need support opportunities to develop cultural competences, and to learn with and about the groups they want to serve."

Finally, researchers and evaluators should make an effort to produce research projects which are methodologically more and more accurate, passing the test of peer review and able to be published in specialized magazines; at the same time, they invite them to concentrate also on results dissemination, to be also useful to professionals and educators, in order to direct their efforts.

Addressing again the directions future research is to take, the authors highlight the last issue, the most problematic one, which should be tackled: the issue of cumulative outcomes of learning:

"Such research would allow researchers to examine the influence of experiences in different settings over time and to explore how their experiences build on or connect to each other. It will require developing and refining research methods for tracking individuals over time and solving other problems pertaining to security of participants' personal information and attrition".

The document is not easy to read, but it certainly offers the patient reader much food for thought and, most of all, some valuable bibliographic references. Now what is needed is some work to build some bridges to link the American experience to the experience in Europe and in other continents. An integration of views, practices and observation would probably fill many gaps, which are not always the same in the various communities of professionals and researchers.

Clearly this review was born in the US and is addressed to the US, and it does not have the pretentiousness to present a global state of the art. On the other hand, an effort to look at other cultures and languages, even quite briefly, would have probably now launched the building of the paths which are to link researchers and operators all over the world.

Translated by Massimo Caregnato

\section{Notes and references}

\footnotetext{
${ }^{1}$ P. Bell, B. Lewenstein, A.W. Shouse and M.A. Feder (eds), Learning Science in Informal Environments: People, Places, and Pursuit,. The National Academy Press, Washington DC, Advanced Copy, January 14, 2009.

${ }^{2}$ M. Cardella and P. Rodari, Science is not my thing. Visitors' attitudes towards learning in an Italian science centre, Informal Learning and Public Understandingof Physics, 3th International GIREP Seminar 2005, Selected contributions, University of Ljubljana, Lubiana 2006.

${ }^{3}$ Among the published studies see also: C. Schreiner and S. Sjøberg, Science education and youth's identity construction - two incompatible projects?, in: D. Corrigan, J. Dillon and R. Gunstone (eds.), The Re-emergence of Values in the Science Curriculum. Rotterdam: Sense Publishers 2007, available at http://www.ils.uio.no/english/rose/network/countries/norway/eng/nor-schreiner-values2006.pdf;

S. Sjøberg, Science and scientists: The SAS-study Cross-cultural evidence and perspectives on pupils interests, experiences and perception, Acta Didactica 1, University of Oslo, Revised and enlarged version, 2002;

E.W. Jenkins and N.W. Nelson, Important but not for me: students' attitudes towards secondary school science in England, Research in Science \& Technological Education, 23(1) May 2005;

J. Osborne et al., What "Ideas-about-science" should be taught in School Science?, Journal of Research in Science Teaching 40(7), 2003.

${ }^{4}$ The latest document published in this regard comes from the Department for Business, Innovation and Skills of the UK government: The Government's Approach on Public Dialogue on Science and Technology, http://www.sciencewise-erc-gov-uk; a relevant project to the formation of scientific citizenship, still coming from the UK, is Citizenscience: http://www.atbristol.org.uk/cz/; concerning education to scientific citizenships, see also: L. D’Angelo, P. Rodari and F. Sgorbissa (Eds.), Science Education for the Development of European Citizenship. Suggestions, proposals, data and results from a Comenius 2.1 European Project, Trieste: Sedec 2008.
}

How TO CITE: $\quad$ P. Rodari, Learning science in informal environments: people, places and pursuits. A review by the US National Science Council, Jcom 08(03) (2009) R02. 